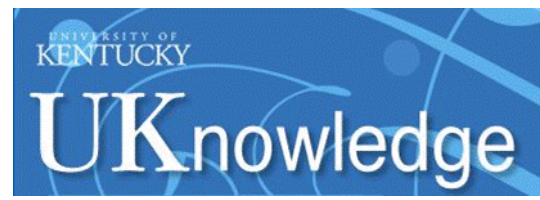

University of Kentucky

UKnowledge

6-1-2016

\title{
Microstructural Properties and Four-Point Bend Fatigue Behavior of Ti-6.5Al-2Zr-1Mo-1V Welded Joints by Electron Beam Welding
}

\author{
Peng Liu \\ Shandong Jianzhu University, China \\ Tongguang Zhai \\ University of Kentucky, tongguang.zhai@uky.edu \\ Yuanbin Zhang \\ Shandong Jianzhu University, China
}

Follow this and additional works at: https://uknowledge.uky.edu/cme_facpub

Part of the Chemical Engineering Commons, and the Materials Science and Engineering Commons Right click to open a feedback form in a new tab to let us know how this document benefits you.

\section{Repository Citation}

Liu, Peng; Zhai, Tongguang; and Zhang, Yuanbin, "Microstructural Properties and Four-Point Bend Fatigue Behavior of Ti-6.5Al-2Zr-1Mo-1V Welded Joints by Electron Beam Welding" (2016). Chemical and Materials Engineering Faculty Publications. 25.

https://uknowledge.uky.edu/cme_facpub/25

This Article is brought to you for free and open access by the Chemical and Materials Engineering at UKnowledge. It has been accepted for inclusion in Chemical and Materials Engineering Faculty Publications by an authorized administrator of UKnowledge. For more information, please contact UKnowledge@lsv.uky.edu. 


\title{
Microstructural Properties and Four-Point Bend Fatigue Behavior of Ti-6.5Al-2Zr-1Mo-1V Welded Joints by Electron Beam Welding
}

\author{
Digital Object Identifier (DOI) \\ https://doi.org/10.1515/htmp-2015-0033 \\ Notes/Citation Information \\ Published in High Temperature Materials and Processes, v. 35, issue 6, p. 607-613. \\ @ 2016 by De Gruyter.
}

The copyright holder has granted the permission for posting the article here. 
Peng Liu*, T. Zhai and Yuanbin Zhang

\section{Microstructural Properties and Four-Point Bend Fatigue Behavior of Ti-6.5Al-2Zr-1Mo-1V Welded Joints by Electron Beam Welding}

DOI 10.1515/htmp-2015-0033

Received February 5, 2015; accepted June 16, 2015

\begin{abstract}
With the help of a four-point-bend of fatigue rig, high-cycle fatigue tests were carried out on an Ti-6.5Al2Zr-1Mo-1V titanium alloy at room tempcrature, $20 \mathrm{~Hz}$ and $R=0.1$ in ambient air. The test results indicated that the fatiguc strength of base metal, $888 \mathrm{MPa}$, is about $120 \%$ of yield strength. The fatigue strength of joints is $814 \mathrm{MPa}$. It is about $110 \%$ of yield strength of base metal. When the loading stress is higher, the fatigue failure region is located in middle weld zone of weld face, which the cracks are propagated along coarse $\beta$ phase's grain boundary. When the loading stress is lower, the fatigue failure region is located between the incomplete recrystallization zone and base metal. The crack nucleation resistance gradually increases from the WN to $\mathrm{HAZ}$ with the variable of loading stress and $\beta$ phase (little $\alpha^{\prime}$ phases) $\rightarrow \alpha+\beta$ phase $\rightarrow \alpha$ phase.
\end{abstract}

Keywords: titanium alloy, clectron beam welding, bending fatiguc, microstructure

\section{Introduction}

Titanium alloys are used in acrospace and a wide variety of other industries because of their high specific strength, good ductility, and excellent fatigue properties [1, 2]. Ti-6.5Al-2Zr-1Mo-1V (wt.\%) is one new type alloys of the most important titanium alloys used in aircraft engine components. These components are subjected to high cycle fatigue (HCF) loading induced by high-frequency vibrations [3]. The high cycle fatigue process consists of two stages, namely, fatigue crack initiation and fatigue crack growth [4]. And some components were used in the form of important welding structures [5]. Therefore,

*Corresponding author: Peng Liu, School of Materials Science and Engineering, Shandong Jianzhu University, Jinan 250101, P.R. China, E-mail: liupeng1286@163.com

T. Zhai, Department of Chemical and Materials Engineering, University of Kentucky, 177 Anderson Hall, Lexington, KY 40506, USA Yuanbin Zhang, School of Materials Science and Engineering, Shandong Jianzhu University, Jinan 250101, P.R. China compared with titanium alloys that were used as components directly, the high cycle fatigue loading of welding structures subjected has more influence on service life. As a result, it is important to analyze and clear the fatigue crack initiation and fatigue crack growth.

At present, the titanium alloys as important components can be joined by a variety of welding methods, such as electron beam welding (EBW) [6], laser beam welding (LBW) $[7,8]$, linear friction welding (LFW) [9], friction stir welding (FSW) [10], gas tungsten welding (GTAW) [11] and tungsten inert gas welding (TIG) [12], among which electron beam welding has drawn particular attention due to its high energy density, a deep and narrow joint, a minimal heat-affected zone (HAZ), low residual stress and small distortion of welded materials [13-15]. Previous studies concerning the welded joints of titanium alloys were mainly focused on microstructure, phase morphology, hardness, tensile and $S-N$ curve properties [16-18]. However, these studies were performed via a method of pulsed tensile fatigue of welded joints. For welded joints, it is important to clearly know the relation between microstructure of all zones (weld zone, heat-affected zone and fusion zone) and fatigue behavior for the welded joints of titanium alloys. And the existing methods about the fatigue analysis for welded joints are not enough to analyze and evaluate the effect of microstructural evolution on the fatigue behavior of welded joints. However, the four-bend test improved propagation $[19,20]$. This method using the optimum testing geometry in the four-point bend is a novel technology to minimize some factors which affected the exact fatigue test. And Professor T. Zhai also provides a great deal of excellent features in studying the crack initiation and possible misalignment associated with fatigue test. Now, it has shown good merits to gauge the fatigue behavior of aluminum alloys, magnesium alloys and titanium alloys, which can provide a special analysis method about effect of structure in all micro-regions on the fatigue behavior. In this work, we used the four-point-bend apparatus to obtain fatigue data for EBW joints of Ti-6.5Al-2Zr1Mo-1V titanium alloy and described the experimental investigations performed to study the crack initiation and micro-crack propagation bchavior of EBW joints. 


\section{Experimental}

The chemical composition of Ti-6.5Al-2Zr-1Mo-1V (TA15) alloys used for this work was shown in Table 1 . The tensile yield strength of the alloy was $740 \mathrm{MPa}$. The thickness of the test plate is $5 \mathrm{~mm}$. TA15 titanium alloy sheets were joined by means of vacuum clectron beam welding (EBW). The welding parameters are the working voltage $150 \mathrm{kV}$, the focus current $2,443 \mathrm{~mA}$, the welding speed $30 \mathrm{~mm} / \mathrm{s}$. After weld. ing, these welded joints were annealed $\left(650^{\circ} \mathrm{C} \times 2 \mathrm{~h}\right)$ by vacuum heat treatment equipment. The main aim is to relicve residual stress by annealing.

Table 1: Chemical composition of the Ti-6.5Al-2Zr-1Mo-1V titanium alloy (wt.\%).

\begin{tabular}{rrrrrrrrr}
\hline Alloys & Al & $\mathbf{V}$ & Mo & Zr & C & Fe & Si & Ti \\
\hline TA15 & 6.72 & 2.32 & 1.77 & 2.19 & 0.0053 & 0.08 & 0.14 & Balance \\
\hline
\end{tabular}

A series of specimens were cut from the welded joints along a longitudinal direction by lining cutting machine. These specimens were made into metallographic samples. Then, these samples were etched using a mixed solution $\mathrm{HF}$ : $\mathrm{HNO}_{3}: \mathrm{H}_{2} \mathrm{O}=1: 3: 5$. The microstructure of welded joints was observed and analyzed by means of metallographic microscopy. Vickers hardness tests were conducted on the cross-sectional plane using Vickers indenter with a $100 \mathrm{~g}$ loading and a load time of $10 \mathrm{~s}$.

The four-point-bend test was used to gauge the fatigue propertics of the titanium alloy. The test was performed in the equipment of MTS 810 Materials Test System. Samples for the tests were cut from the EBW joints. The test geometry and loading states were shown in Figure 1. Before fatigue tests the polishing was carricd out on the surfaces of the samples that were loaded in tension during the test using waterproof SiC polishing papers followed by mechanically polished using a silica colloidal liquid. The fatigue tests with a stress radio $\left(\mathrm{R}, R=\sigma_{\min } / \sigma_{\max }\right)$ of 0.1 were conducted at a frequency of $20 \mathrm{~Hz}$, with a waveform

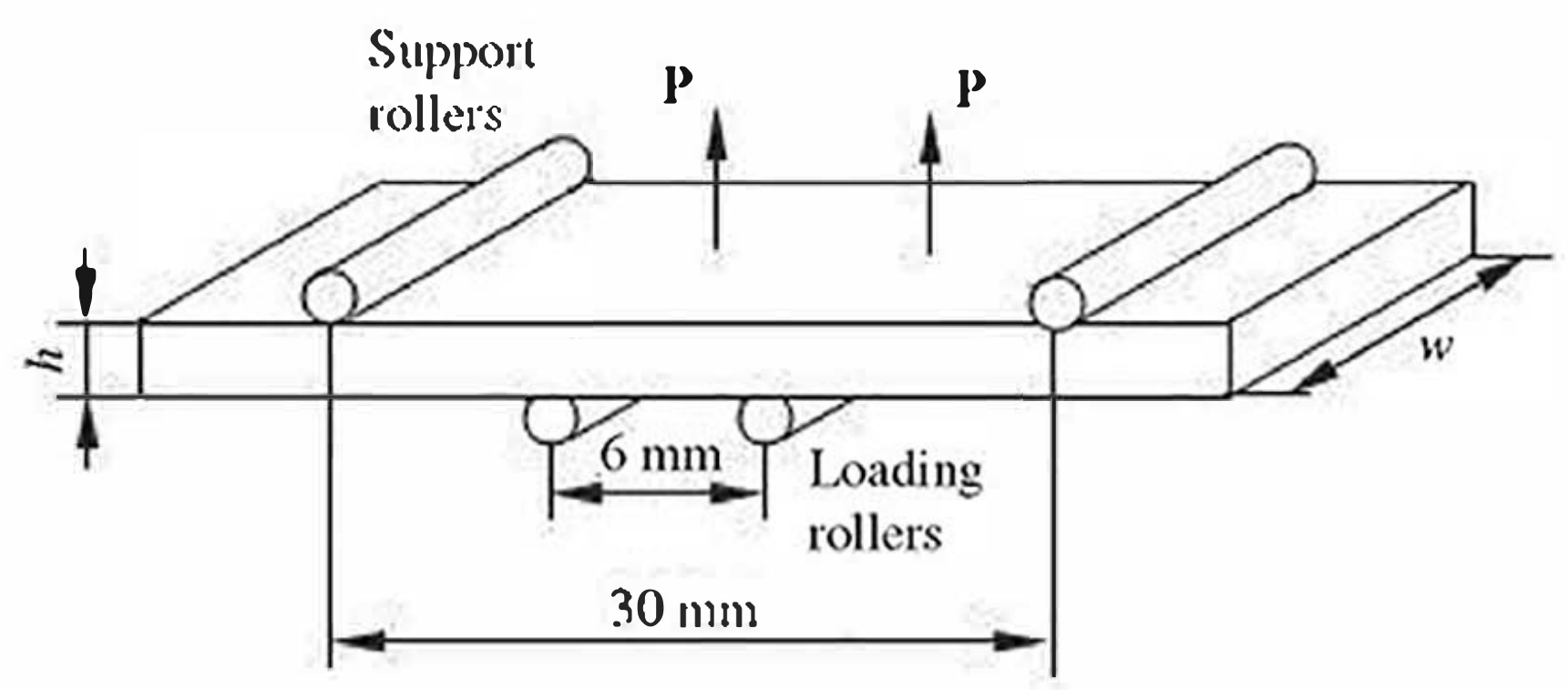

Figure 1: Four-point bend specimens geometry and the loading states. and at room temperature in laboratory air of which the humidity was maintained at about RH 15 pct. Fatigue tests were periodically interrupted for observation and measurement of cracks. After failure, metallographic microscopy was used to investigate the state of surface crack.

\section{Results and discussion}

\section{Microstructure and hardness}

Figure 2 shows the macro-photograph of welded joint for TA15 titanium alloys by clectron beam welding (EBW). The welded joint is composed of weld zone (WZ), heat-affected zone (HAZ) and base metal (BM). The HAZ can be divided into the transformation recrystallization zone and incomplete recrystallization zone. There are a mass of white primary $\alpha$ solid solution phases showed high spheroidization in the base metal (sec Figure 3(a)). And a small amount $\beta$ phases structure were distributed around fine grains, which showed a typical uniform structure constituted by fine lamellar $\alpha$ phases and remaining $\beta$ phases among lamellar $\alpha$ phases [21].

According to Figure $3(\mathrm{~b})$, the crystal grains in the incomplete transformation recrystallization zone are bigger than the one in base metal and showed the coarsening characteristic. However, in this zone the main structural characteristic is the same as base metal. Only since the effect of heat temperature gradient during the welding, the transformation recrystallization is incomplete. As a result, the grain of primary $\alpha$ phases showed coarsening and the $\beta$ phases gradually increasing. For the transformation recrystallization zone, it is located in the transition region between the fusion line and the weld zone. The

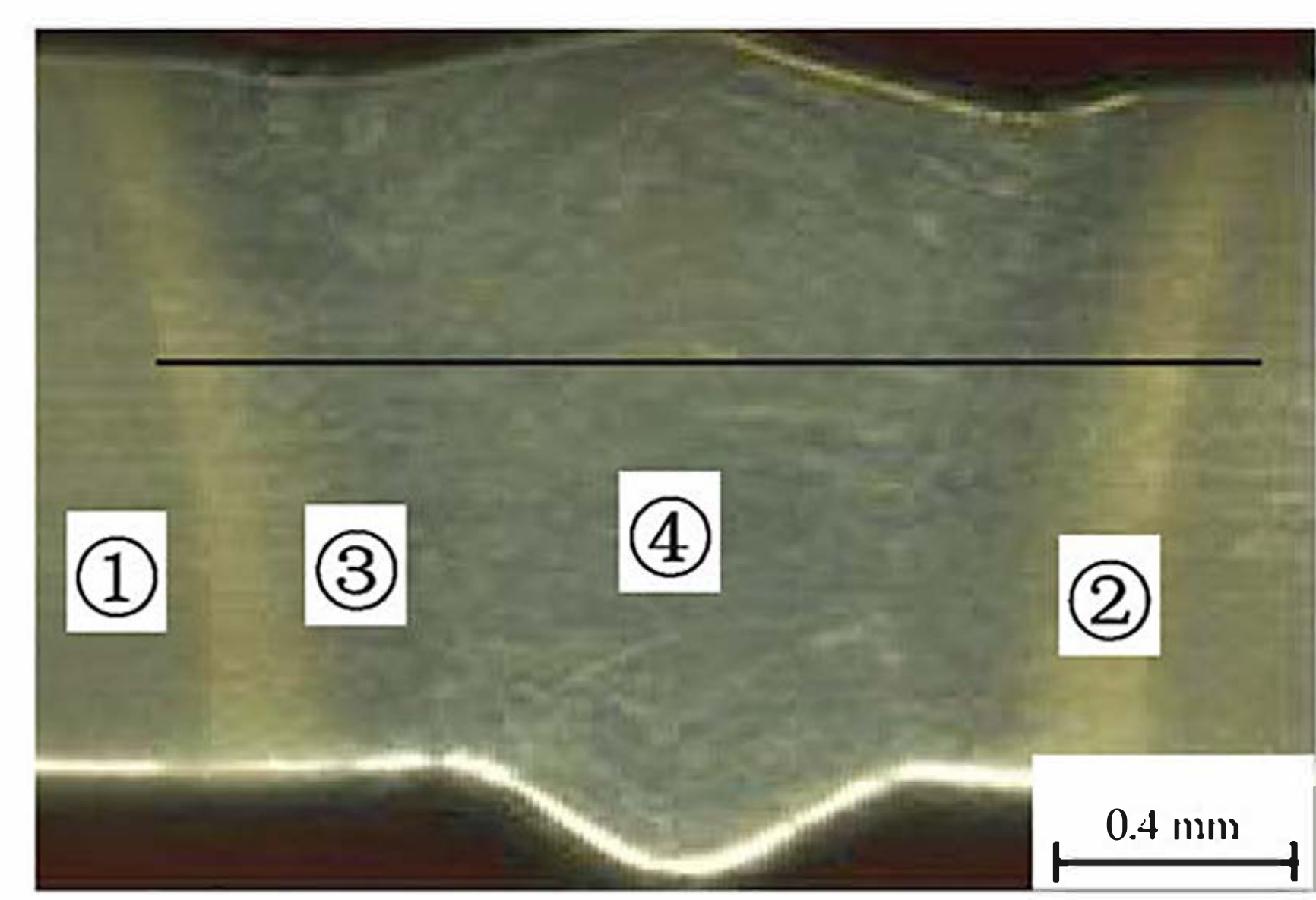

Figure 2: Macro-photograph of welded joint. 


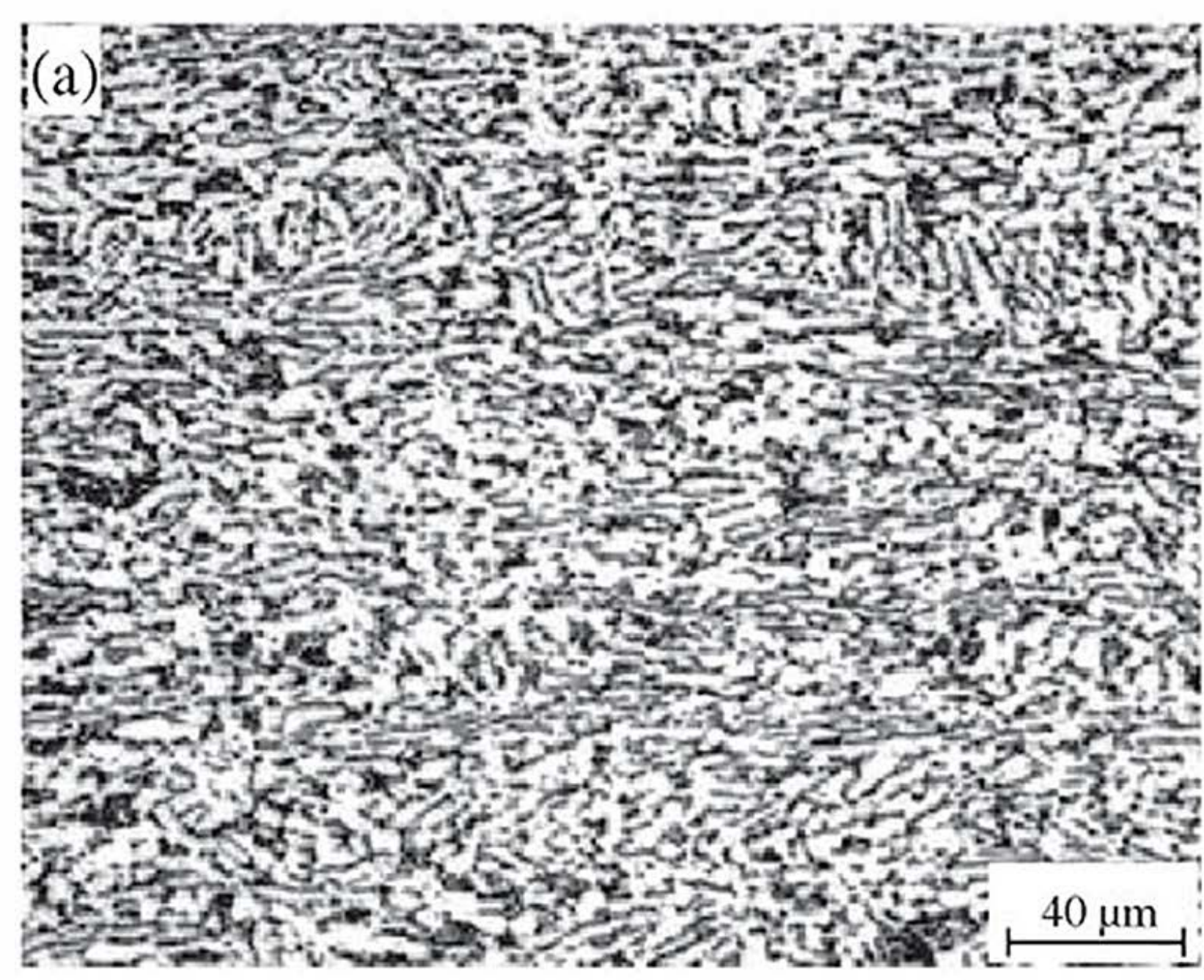

(a) base metal

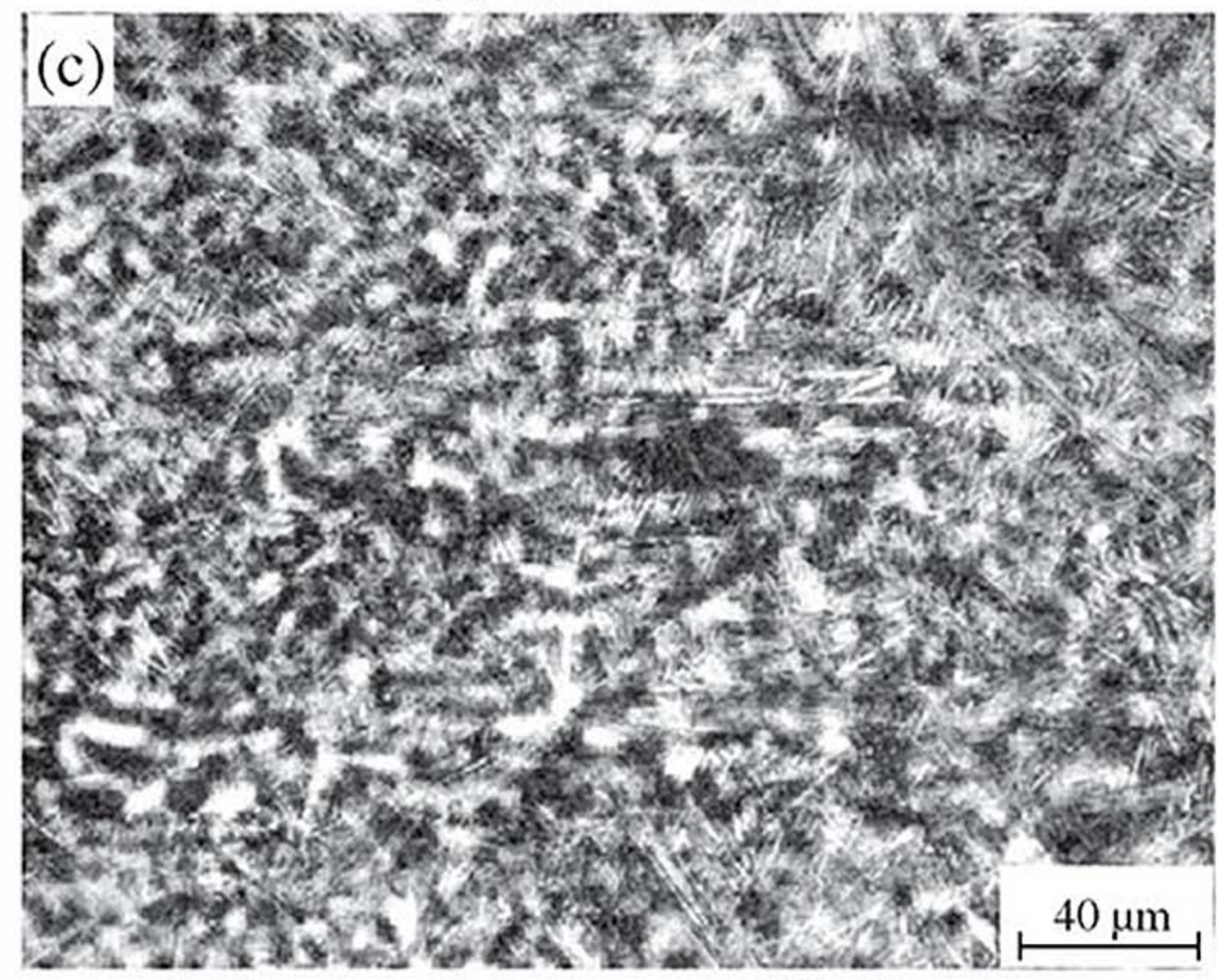

(c) incomplete recrystallization zone

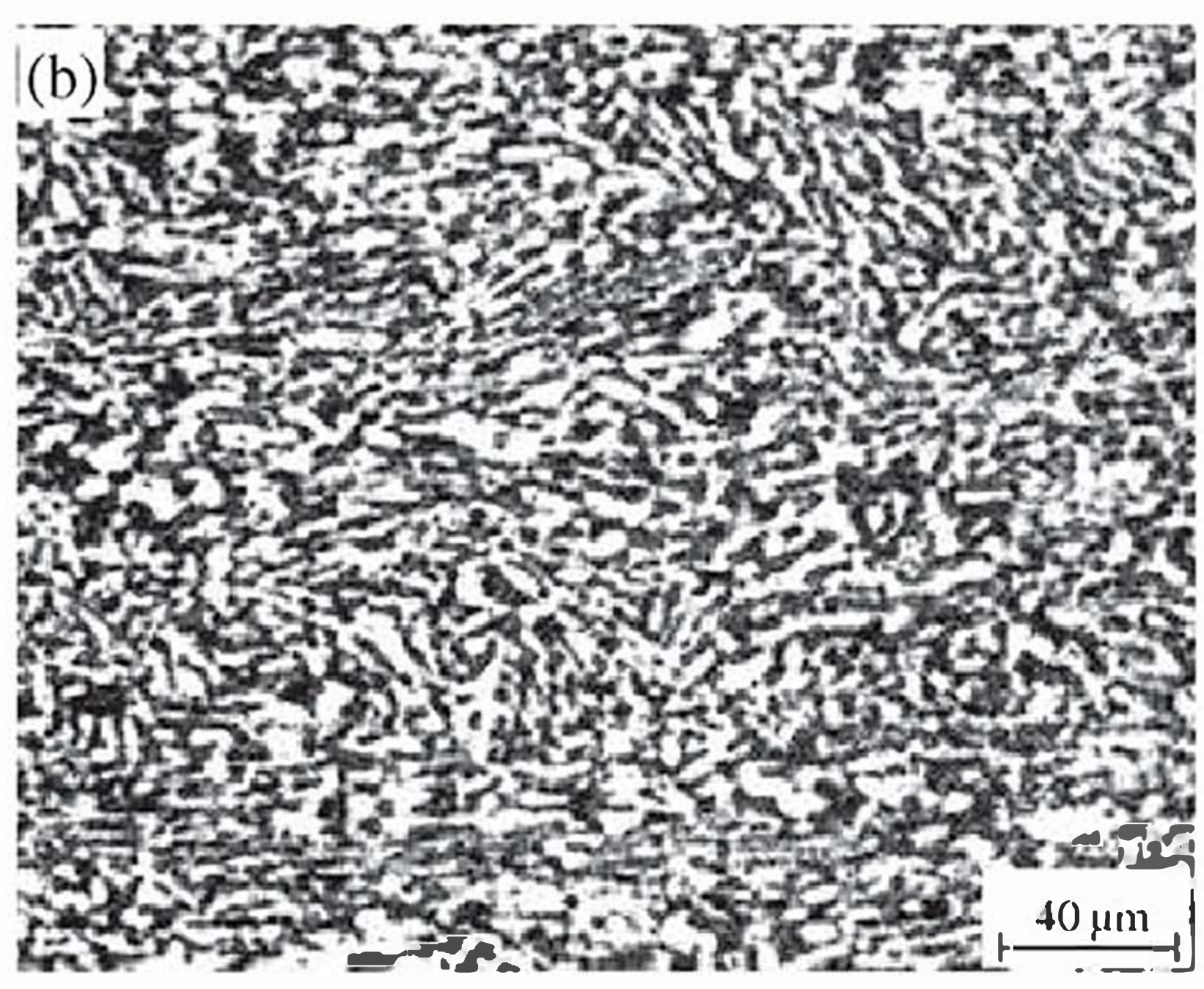

(b) transformation recrystalli\%ation \%one

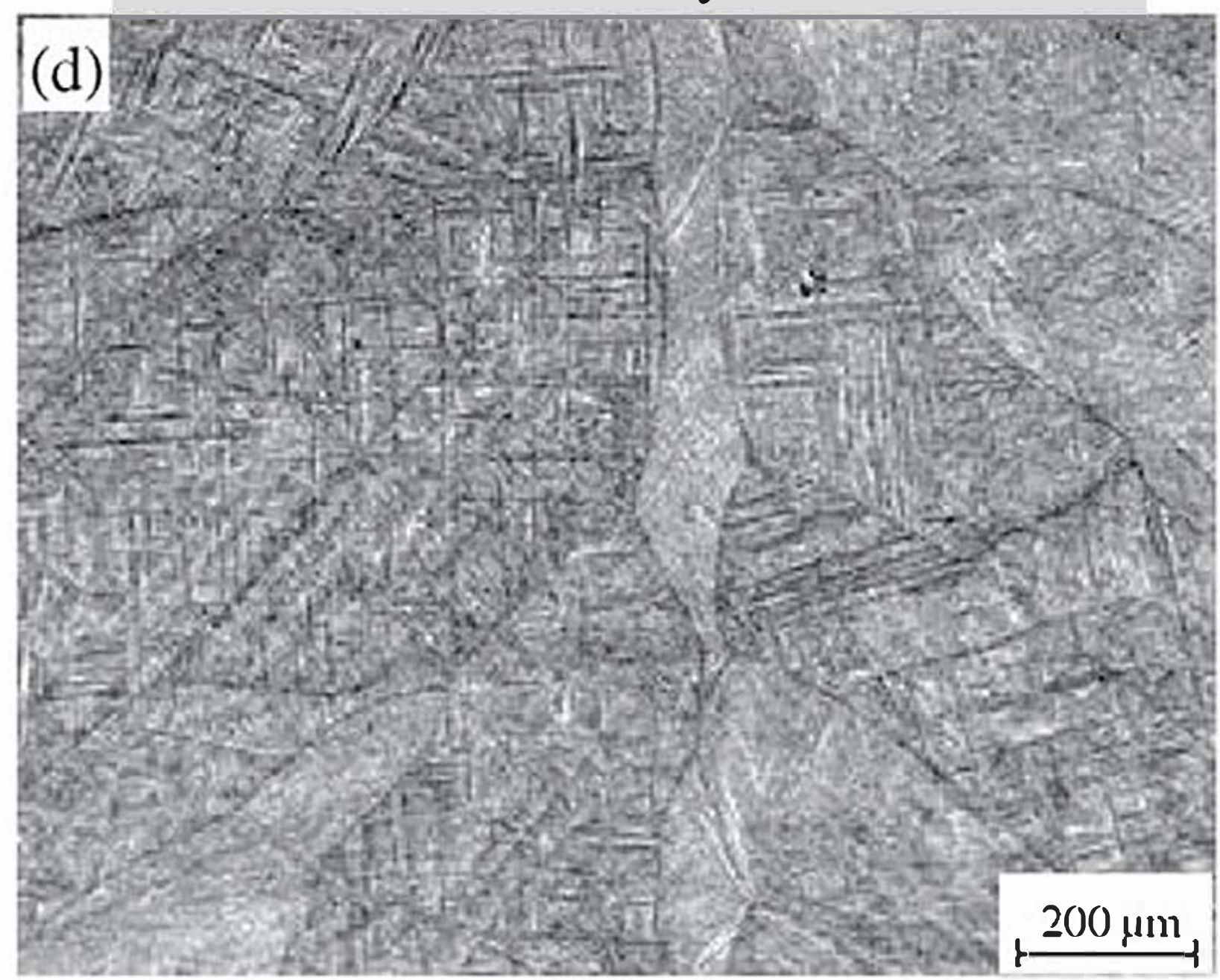

(d) weld zone

Figure 3: Microstructure of EBW joint for TA 15 titanium alloys.

growth of crystal grains were incomplete resulted in the coarsening because of the fast heat speed and short holding time of high temperature (sce Figure 3(c)). Moreover, it is clear that some needle $\alpha^{\prime}$ phases distributed in $\beta$ phases substrate. The distribution of these $\alpha^{\prime}$ phases is non-uniform, crystallizing along the primary grain boundary of $\beta$ phases. Namely, the $\beta$ phases are beginning to increase near the fusion line and the weld zone. The microstructure of weld zone is shown in Figure 3(d). In this zone metals were completely melted and experienced a high temperature with a long holding time, which caused an obvious structure transformation. A mass of coarse $\beta$ phase's grains existed in this zone, which precipitated needle $\alpha^{\prime}$ phases along $\beta$ grain boundary (martensite structure). This reason is that the fast growth speed of $\beta$ phase's grains suffered the effect of super high temperature formed the coarse original $\beta$ phases. Then, during the cooling, the needle $\alpha^{\prime}$ phases were precipitated along the $\beta$ grain boundary. It is well known that the martensite structure formed in the weld zone was unfavorable to improve the performance of welded joints.

The microstructure is complicated of EBW joints for titanium alloys, especially for high hardness phases in weld zone and its bad effect. The microhardness test is an effective method to evaluate the effect of phase transformation. Figure 4 shows the microhardness distribution of EBW joints for TA15 titanium alloys. The test results indicated that the hardness in weld zone and HAZ by means of the annealing treatment is obviously decreased. Especially for HAZ, the maximal hardness is decreased from about $385 \mathrm{HV}$ to about $360 \mathrm{HV}$. And the hardness distribution of the weld zone and HAZ trends a uniform state. It is favorable to improve the service time of welded joints. And the reduction of martensite structure in both zones after the annealing treatment was also an important effect on decreasing the hardness. 


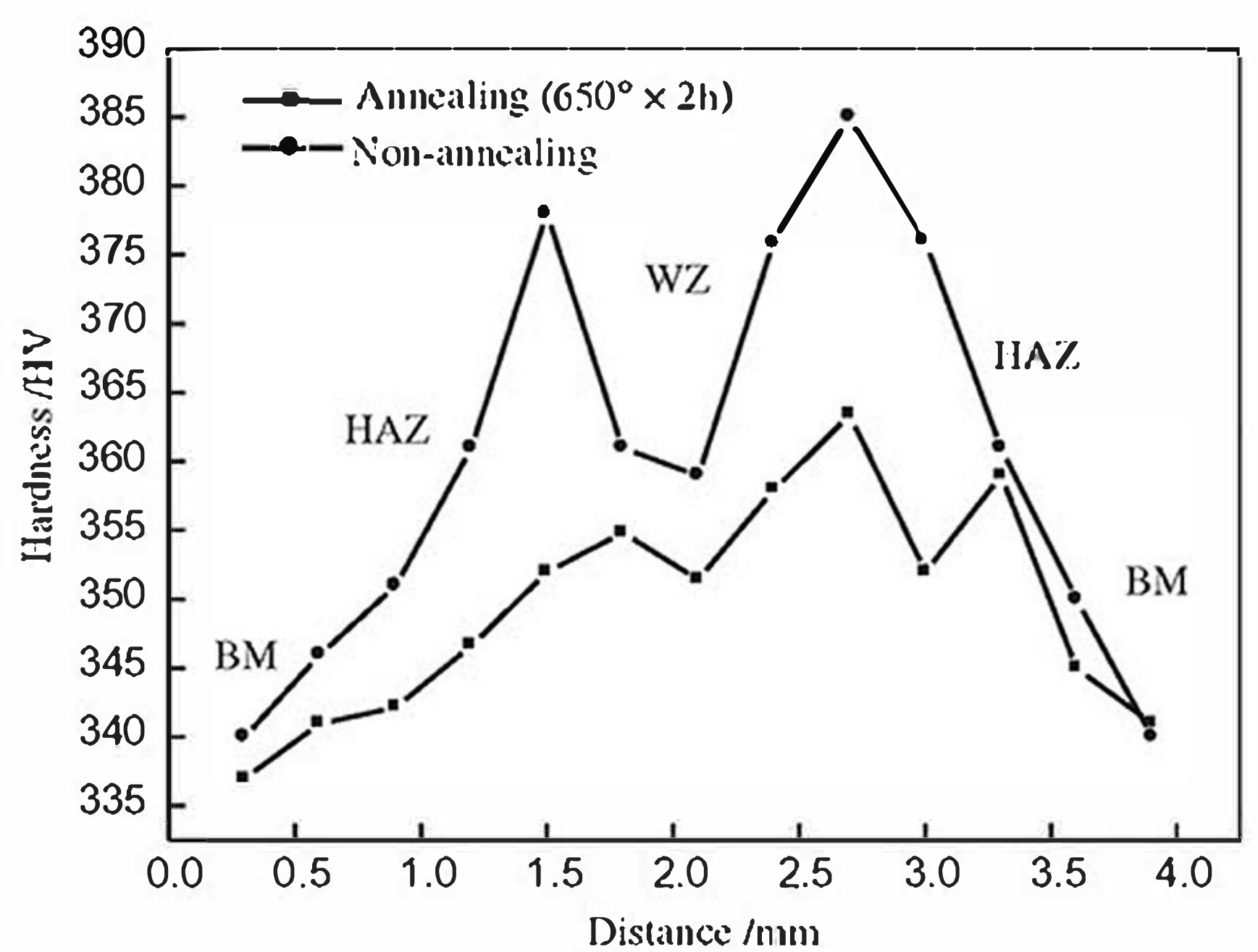

Figure 4: Curve of microhardness distribution of EBW joints for TA15 titanium alloys.

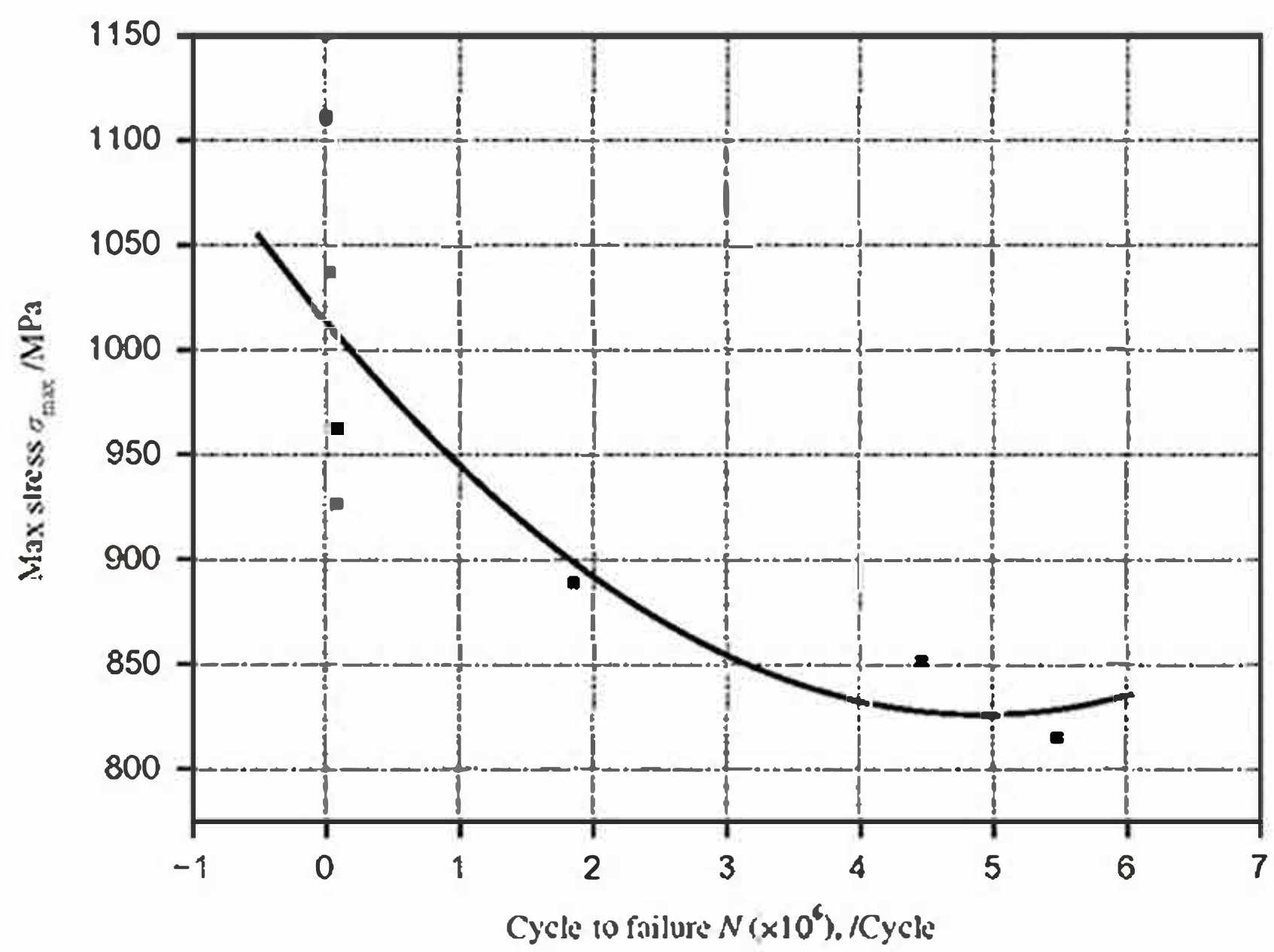

(a) $S-N$ curve $(R=0.1)$ of liBW joints

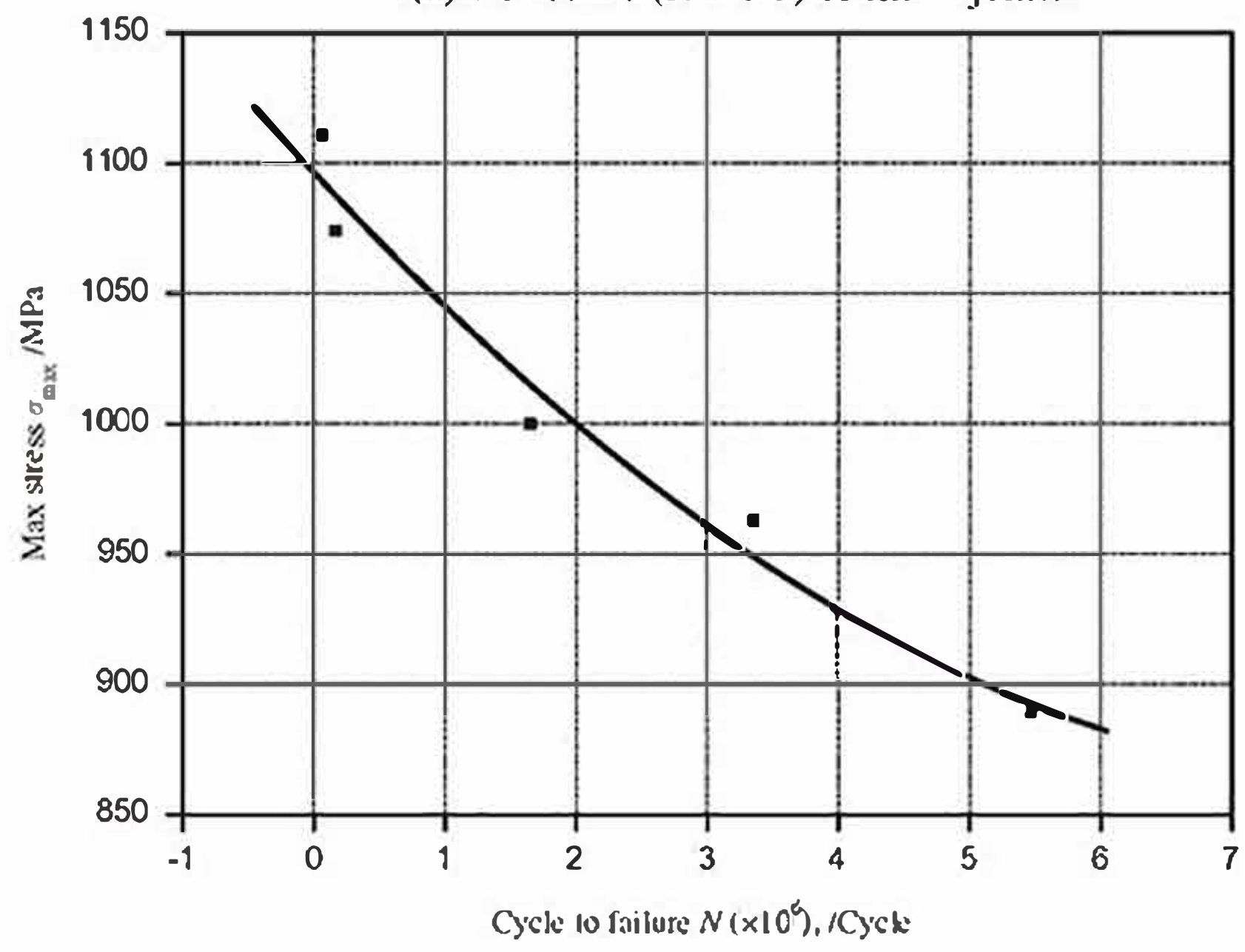

(c) $S$-Ncurve $(R=0.1)$ of base metal

\section{$S-N$ and $S-\lg N$ curves}

According to Figure 1, the four-point bend fatigue test of EBW joints for titanium alloys was preformed. The standard specimens were prepared by lining cutting, including base metal (non-annealing) and welded joints (annealing $650^{\circ} \mathrm{C} \times 2 \mathrm{~h}$ ). During the testing, the yicld strength of base metal, $740 \mathrm{MPa}$, was used. A range of loading stress level is from $150 \%$ to $80 \%$. With the increase of cycle times, the flexibility of specimens would be gradually increased. When the cycles reach to $55,00,000$ times and the specimen has not been destroyed, the loading stress is as the fatigue strength or fatigue limitation of materials tested. After the testing, the distribution characteristics of cracks in the surface of specimens will be observed by optical microscope. The curve of fatigue testing can be seen in Figure 5.

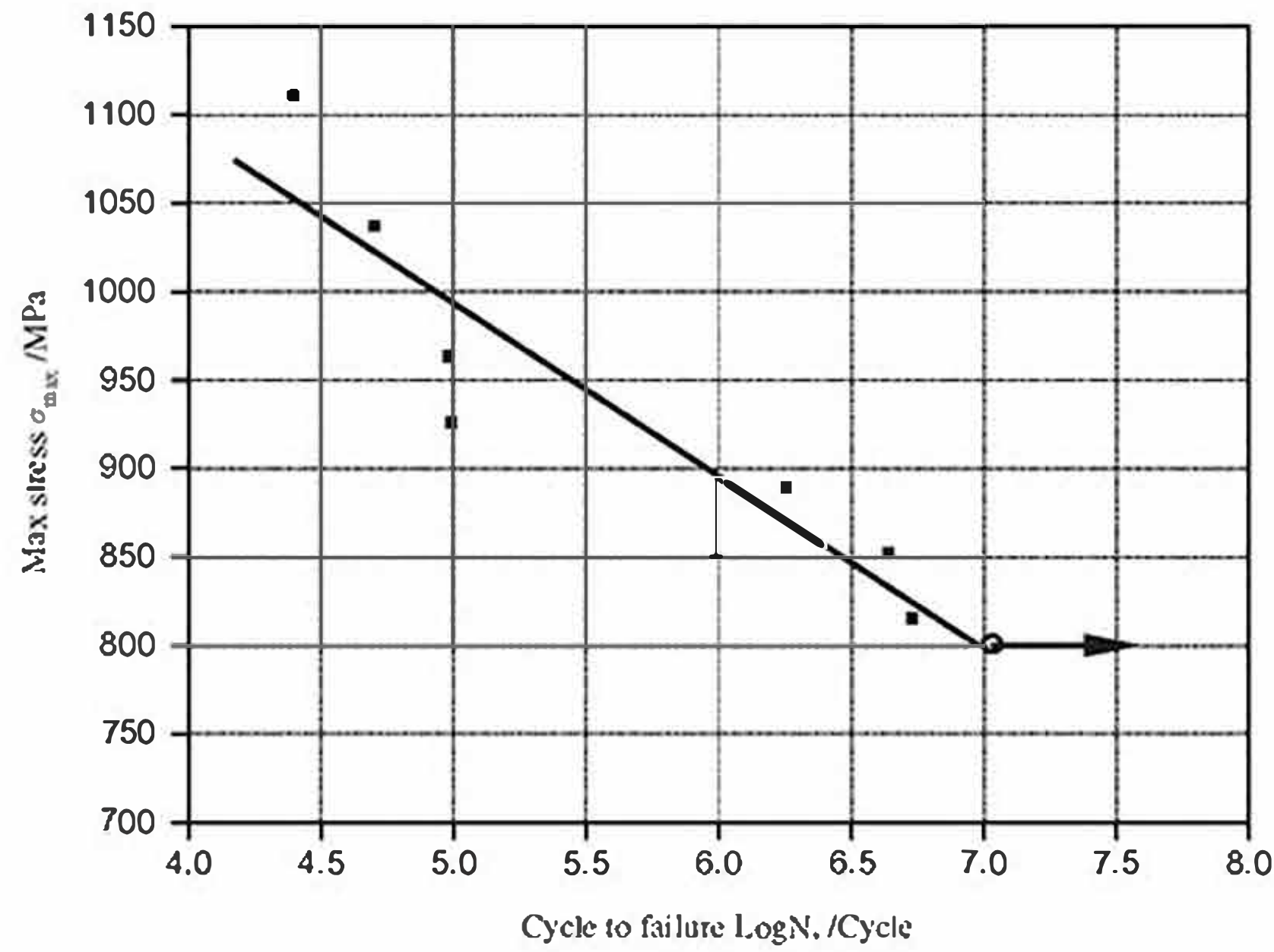

(b) $S$-lgN curve $(R=0.1)$ of li $B W W$ joints

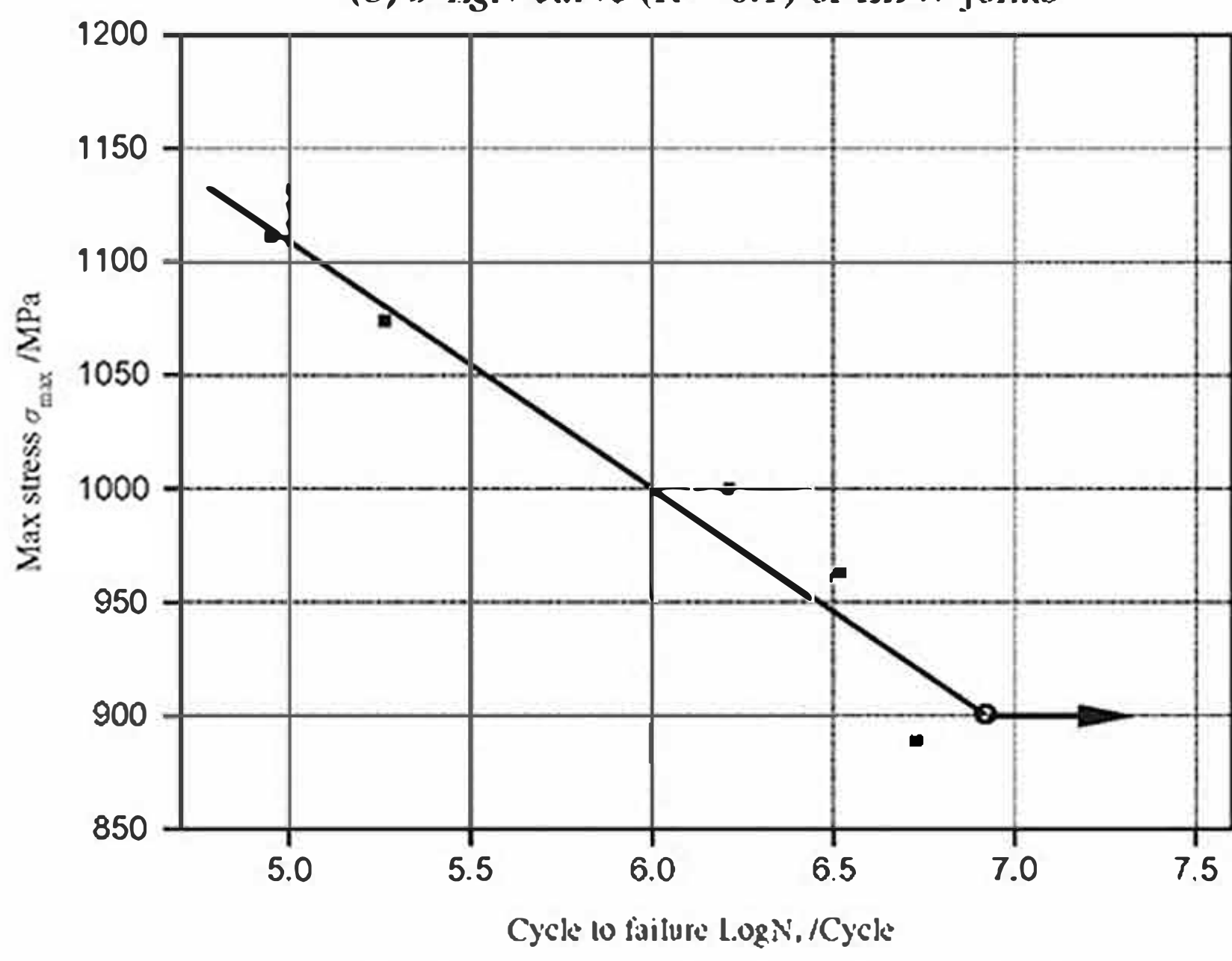

(d) S-l.gN curve (R $=0.1)$ of base metal

Figure 5: $S-N$ and $S-L g N$ curves $(R=0.1)$ of four-point bend test of EBW joint for TA15 titanium alloys. 
In Figure 5, with the decrease of loading stress level the fatigue strength of base metal and welded joints increases gradually (see Figure 5(a) and 5(c)). There is an adjacent linear relationship between the stress level (S) and logarithmic transformation of cycles $(\log N)$. It can be seen in Figure 5(b) and 5(d). And the fatigue strength of base metal, $888 \mathrm{MPa}$, is about $120 \%$ of yield strength. The fatigue strength of joints is $814 \mathrm{MPa}$. It is about $110 \%$ of yield strength of base metal and is also closed to the base metal. The test results indicated that the welding joint of titanium alloy experienced the EBW has a high fatigue strength compared with base metal. Therefore, the electron beam welding is one of the best welding methods to join the titanium alloys to obtain a high-quality welding structure. Secondly, some previous studies indicated that the titanium alloys of thin plane had low fatigue strength because of the high residual stress during the welding [22]. However, in this paper when the weld face of joints (the reinforcement of weld) was treated by machining flush and polishing treatment, the joints showed the higher fatigue strength. Therefore, the weld face treated effectively could play an important role to improve the performance of joints. And the test results are similar to some studies performed via a method of pulsed tensile fatigue of EBW joints for TA15 titanium alloys [23]. That is to say, the self-aligning four-point bend testing is suitable for evaluating the fatigue properties of welded joints for thin plane metal.

\section{Crack and fracture characteristics of fatigue}

Above four-point bend fatigue test indicates that the joints showed the higher fatigue strength. So it is important to know the crack and propagation characteristics of failure joints. Figure 6(a) and 6(b) shows the fatigue crack characteristics of the joints under the loading stress $150 \%$ and $120 \%$.

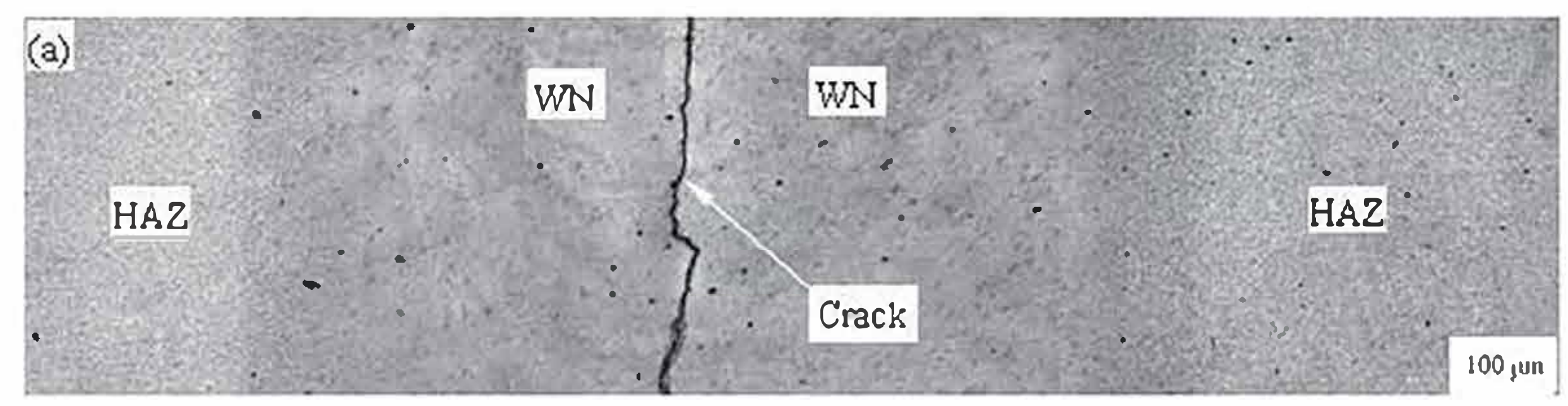

(a) $150 \%$ stress level

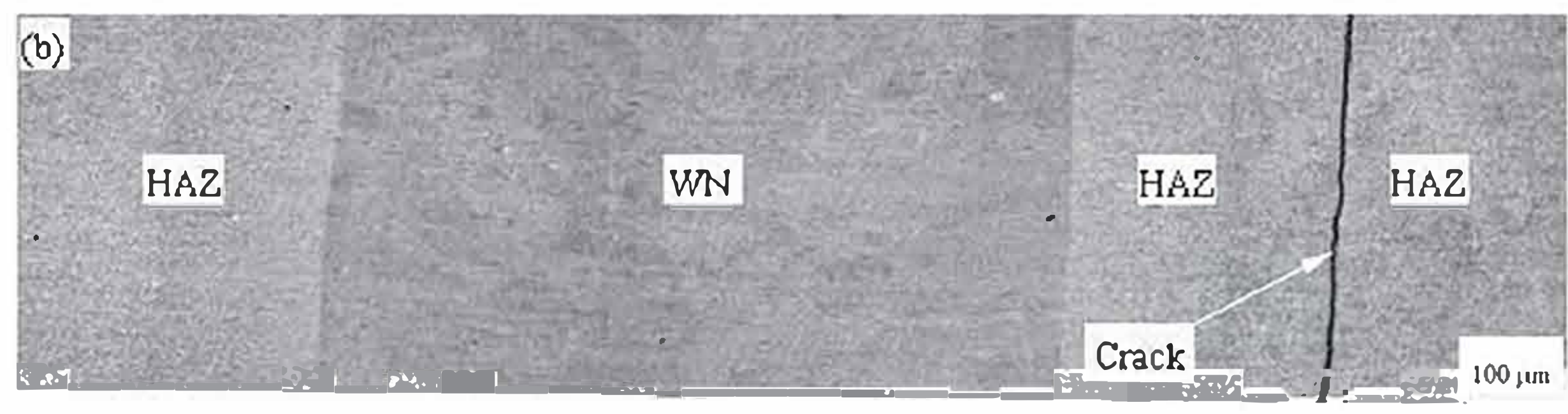

(b) $120 \%$ stress level

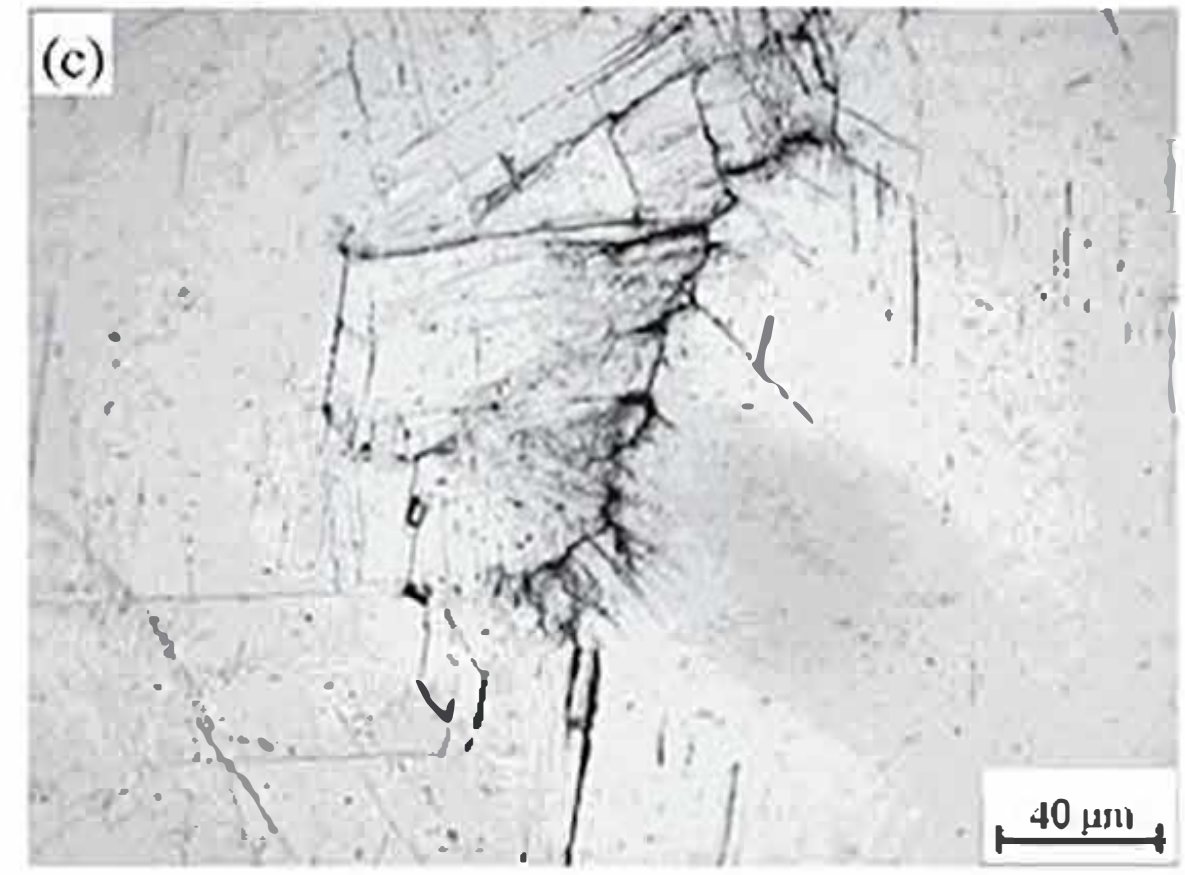

(c) . Microstructure of $150 \%$ stress level

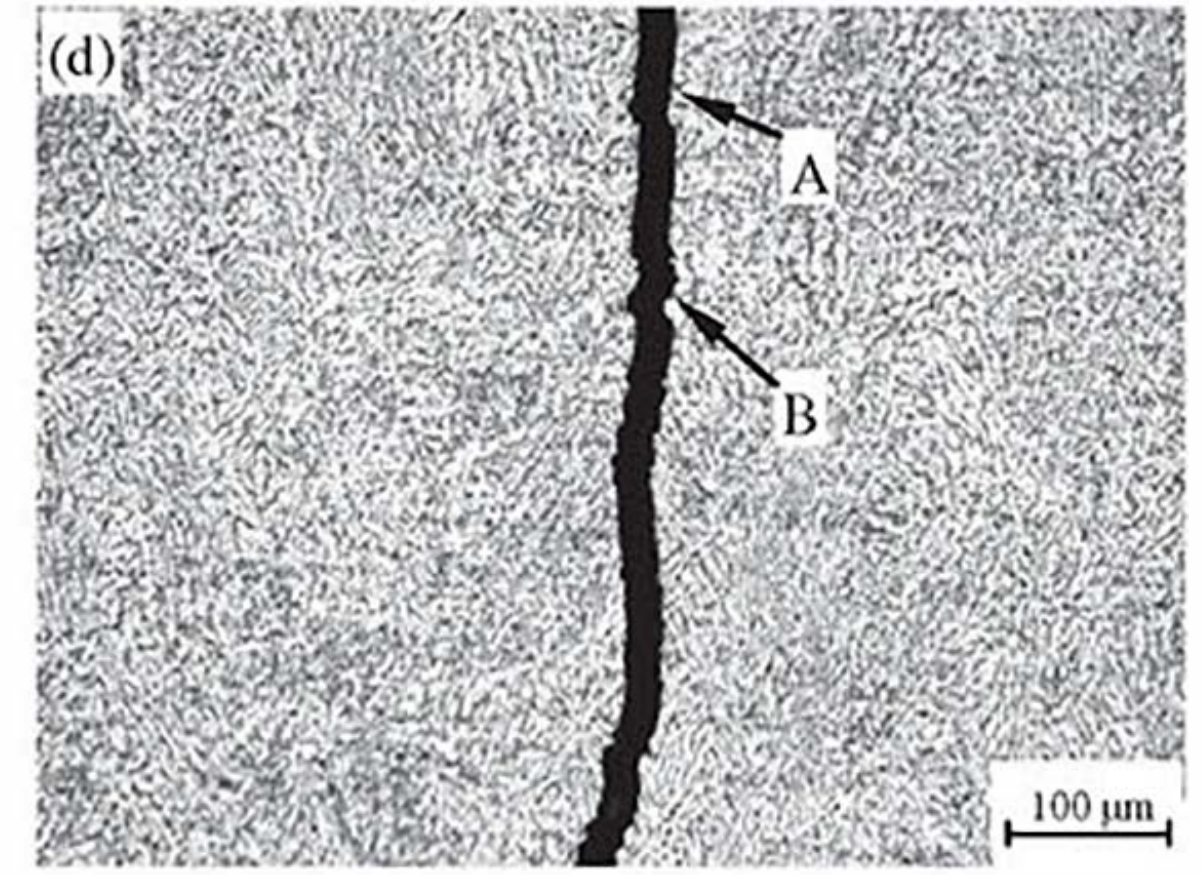

(d) Microstructure of $120 \%$ stress level

Figure 6: Fatigue failure characteristics of $150 \%$ and $120 \%$ stress level. 
Obviously, when the loading stress is $150 \%$ of yicld strength, the fatigue failure region is located in weld middle zone of weld face. And the cracks are propagated along coarse $\beta$ phase's grain boundary (see Figure 6(c)). Therefore, in Figure 6(a), the zigzag crack can be observed clearly. However, when the loading stress, as much as 120 of yield strength, is lower, the fatigue failure region can be observed between the incomplete recrystallization zone and base metal. And the cracks showed the obvious straight and transcrystalline cracking (see Figure 6(d)). Fatigue cracks consistently initiated in the $\alpha$ phase and at the interface $\alpha$ and $\alpha+\beta$ grain, as shown in position $A$ and $B$ (possible) of Figure 6(d). That is to say, it is obvious that under the four-point bend fatigue the variable loading stress has an important effect on the fatigue failure of EBW joints. And the cause is possibly relation to the complex microstructural characteristics of EBW joints. The complex joint shows the great structure transition from $\beta$ phase structure (little $\alpha^{\prime}$ phase) of weld zone to $\alpha+$ little $\beta$ phase structure of HAZ (see Figure 3). And the structure shows the $\alpha+\beta$ phase between the central weld zone and HAZ. The crack nucleation resistance usually becomes weaker as the volume fraction of the $\alpha$ phase increases [24]. Therefore, according to the structural transition in the joint, the crack nucleation resistance gradually increases from the WN to HAZ. In this paper the location of fatigue failure is in the HAZ under the condition of $120 \%$ loading stress. Under the condition of $150 \%$ loading stress, the location of fatigue failure is in the weld zone. It is quite obvious that the fracture toughness of the structure compared with the weld zone which had a mass of coarse $\beta$ phase structure is more favorable to enhance the performance of joints.

\section{Conclusions}

From the experimental studies on microstructural properties and four-point bend fatigue behavior of Ti-6.5Al-2Zr1Mo-1V welded joint by electron beam welding, the following concluding remarks can be drawn:

(1) The crystal grains in the incomplete transformation recrystallization zone are bigger than the one in base metal and showed the coarsening. For the transformation recrystallization zone, it is clear that some needle $\alpha^{\prime}$ phases distributed in $\beta$ phases substrate. A mass of coarse $\beta$ phase's grains existed in the weld zone.
(2) The hardness in the weld zone and HAZ experienced the annealing treatment is obviously decreased. Especially for HAZ, the maximal hardness is decreased from about $385 \mathrm{HV}$ to about $360 \mathrm{HV}$. And the fatigue strength of base metal, $888 \mathrm{MPa}$, is about $120 \%$ of yield strength. The fatigue strength of joints is $814 \mathrm{MPa}$. It is about $110 \%$ of yicld strength of base metal and is also closed to the base metal.

(3) When the loading stress is $150 \%$ of yield strength, the fatigue failure region is located in the middle weld zone of weld face. And the cracks are propagated obviously along coarse $\beta$ phase's grain boundary. When the loading stress, as much as $120 \%$ of yicld strength, is lower, the fatigue failure region can be observed between the incomplete recrystallization zone and base metal.

Funding: This research was financially supported through the National Natural Science Foundation of China (Grant No. 51305240).

\section{References}

[1] O. M. Ivasishin, S. L. Semiatin, P. E. Markovsky, S. V. Shevchenko and S. V. Ulshin, Mater. Sci. Eng. A, 337 (2002) 88-96.

[2] Z. F. Zhang, H. C. Gu and X. L. Tan, Mater. Sci. Eng. A, 252 (1998) 85-92.

[3] R. K. Nalla, J. P. Campbell and R. 0. Ritchie, Int. J. Fatigue, 24 (2002) 1047-1062.

[4] J. Schijve, Int. J. Fatigue, 25 (2003) 679-702.

[5] T. S. Balasubramanian, V. Balasubramanian and M. A. Muthumanikkam, J. Mater. Eng. Perf., 20 (2011) 1620-1630.

[6] R. Pederson, F. Niklasson, F. Skystedt and R. Warren, Mater. Sci. Eng. A, 252 (2012) 555-565.

[7] Z. L. Lei, Z. J. Dong, Y. B. Chen, L. Huang and R. C. Zhu, Mater. Sci. Eng. A, 559 (2013) 909-916.

[8] P. L. Threadgill, Mater. Sci. Eng. A, 192/193 (1995) 640-646.

[9] M. Karadge, M. Preuss, C. Lovell, P. J. Withers and S. Bray, Mater. Sci. Eng. A, 459 (2007) 182-191.

[10] U. Dressler, G. Biallas and U. A. Mercado, Mater. Sci. Eng. A, 526 (2009) 113-117.

[11] A. Ravi Shankar, G. Gopalakrishnan, V. Balusamy and U. K. Mudali, J. Mater. Eng. Perf., 18 (2009) 1116-1123.

[12] X. L. Gao, L. J. Zhang, J. Liu and J. X. Zhang, Mater. Sci. Eng. A, 559 (2013) 14-21.

[13] J. Kim and Y. Kawamura, Scr. Mater., 65 (2011) 1033-1036.

[14] J. Kim and Y. Kawamura, Scr. Mater., 56 (2007) 709-712.

[15] A. K. Lakshminarayanan and V. Balasubramanian, Mater. Manuf. Processes, 26(2011) 868-877. 
[16] I. Tomashchuk, P. Sallamand, H. Andrzejewski and D. Grevey, Intermetallics, 19 (2011) 1466-1473.

[17] S. Q. Wang, J. H. Liu and D. L. Chen, Mater. Des., 49 (2013) 716-727.

[18] X. G. Yang, S. L. Li and H. Y. Qi, Mater. Sci. Eng. A, 597 (2014) 225-231.

[19] T. Zhai, Y. G. Xu, J. W. Martin, A. J. Wilkinson and G. A. D. Briggs, Int. J. Fatigue, 21 (1999) 889-894.
[20] X. P. Jiang, C. -S. Man and M. J. Shepard, Mater. Sci. Eng. A, 468-470 (2007) 137-143.

[21] G. Yao, J. W. Li, Y. H. Lu and Z. C. Li, The Chin. J. Nonferrous Metals, 10 (2010) 819-821.

[22] Q. Guan, Weld. in the World, 43 (1999) 64-74.

[23] L. F. Wang, J. 2. Liu and B. R. Hu, Trans. the Chin. Weld. Institution, 28 (2007) 97-100.

[24] G. Lutjering, Mater. Sci. Eng. A, 243(1998) 32-45. 